\title{
W-B-N sputter-deposited thin films for mechanical application
}

\author{
C. Louro ${ }^{\mathrm{a}, *}$, R. Lamni ${ }^{\mathrm{b}}$, F. Lévy ${ }^{\mathrm{b}}$ \\ a ICEMS, Departamento de Engenharia Mecânica - Polo II-Universidade de Coimbra, 3030-29 Coimbra, Portugal \\ ${ }^{\mathrm{b}}$ Institut of Physics of Complexe Matter, EPFL, Ch-1015 Lausanne, Switzerland
}

Available online 7 April 2005

\begin{abstract}
The structure, composition and hardness of reactively sputtered W-B-N thin films were investigated by XRD, EPMA, and Vickers ultramicroindentation.

The chemical composition of the films was changed from $\mathrm{W}_{80} \mathrm{~B}_{20}$ to $\mathrm{W}_{42} \mathrm{~B}_{9} \mathrm{~N}_{49}$ by varying the partial pressure of $\mathrm{N}_{2}$. All the as-deposited coatings were amorphous, except the $\mathrm{W}_{60} \mathrm{~B}_{17} \mathrm{~N}_{23}$ film, which showed crystalline peaks, indexed as bcc $\alpha$-W, overlapping the amorphous feature. This nanocomposite structure lead to a maximum as-deposited hardness of $36 \mathrm{GPa}$.

The coatings were thermally annealed at 850 and $950{ }^{\circ} \mathrm{C}$ in $\mathrm{Ar} / \mathrm{H}_{2}$ atmosphere. All the films crystallised with the formation of the bcc $\alpha$ $\mathrm{W}$ and/or the $\mathrm{fcc}-\mathrm{W}_{2} \mathrm{~N}$ phases, depending on their $\mathrm{B}$ and $\mathrm{N}$ contents. A small increase in hardness was registered for $850{ }^{\circ} \mathrm{C}$ annealing temperature in comparison to the as-deposited state. However, an inverse trend was detected after post-annealing at $950{ }^{\circ} \mathrm{C}$, which was more evident for the high $\mathrm{N}$ content films. This behaviour was attributed to the formation of a soft external layer of boron nitride poorly crystallised.
\end{abstract}

(C) 2005 Elsevier B.V. All rights reserved.

Keywords: W-B-N coatings; Sputtering; Nanostructures; Hardness

\section{Introduction}

Solid-state amorphisation reactions were first reported in 1983 [1]. Since this initial report, numerous other systems have been found in which thin films do not react to form compounds, but instead interdiffuse to form stable amorphous alloys. An example is the case of tungsten-based binary systems, W-N/C, which could be amorphised by the addition of a third element, metallic or non-metallic [2], using the sputtering technique. Among all the W-N/C-M, $\mathrm{M}=\mathrm{Co}, \mathrm{Fe}, \mathrm{Ni}, \mathrm{Si}$, etc... amorphous systems, special attention should be given to W-Si-N as hard coating for mechanical applications, due to the nanocomposite structure, $n c-\mathrm{W}_{2} \mathrm{~N} / \mathrm{a}-\mathrm{Si}_{3} \mathrm{~N}_{4}$ or $\mathrm{nc}-\mathrm{W} / \mathrm{a}-\mathrm{Si}_{3} \mathrm{~N}_{4}$, achieved after thermal annealing up to $1000{ }^{\circ} \mathrm{C}$, allowing a good mechanical stability at high temperatures in both inert [3] and oxidant atmospheres [4]. Based on this viewpoint, it is

\footnotetext{
* Corresponding author.

E-mail address: cristina.louro@dem.uc.pt (C. Louro).
}

our intention to evaluate the influence of another nonmetallic element, boron, in the mechanical behaviour of $\mathrm{W}$ based sputtered coatings, particularly for the W-B-N system. Compared to sputtered Ti-B-N coatings, little research work has been carried out on the W-B-N system. The few exploratory investigations [5-8] showed that this ternary system is an excellent diffusion barrier, due to a dense amorphous structure, relatively high crystallisation temperature and chemical inertness.

The present work is devoted to W-B-N sputter-deposited thin films. Besides the structural characterisation, this work studies the mechanical behaviour by comparing hardness results in as-deposited state and after thermal annealing.

\section{Experimental work}

W-B-N films were deposited by sputtering a $\mathrm{W}_{2} \mathrm{~B}$ target $(150 \times 150 \times 70 \mathrm{~mm})$ with a power density of $8 \mathrm{Wcm}^{-2}$ and a substrate bias voltage of $-70 \mathrm{~V}$, under constant temperature $\left(\cong 450{ }^{\circ} \mathrm{C}\right)$. The $\mathrm{N}_{2} /$ Ar partial pressure ratio varied 
within the range $0-1$, for a total deposition pressure of 0.3 $\mathrm{Pa}$. The coatings, with thickness in the range $2.5-3 \mu \mathrm{m}$ were deposited on Fecralloy substrates (Fe: $72.8 \%$, Cr: $22 \%$, Al: 5\%, Y: $0.1 \%$, Zr: 0.1\% (Goodfellow); $\mathrm{H}_{\mathrm{s}}=2.7 \mathrm{GPa}$ ). The substrates were polished with diamond paste down to a particle size of $1 \mu \mathrm{m}$. Thermal annealing process was carried out at 850 and $950{ }^{\circ} \mathrm{C}$ for $30 \mathrm{~min}$ in an $\mathrm{Ar} / \mathrm{H}_{2}$ atmosphere with a working pressure of $5 \mathrm{~Pa}$, after a base pressure of $10^{-3}$ $\mathrm{Pa}$. A Cameca SX-50 electron probe microanalysis (EPMA) apparatus was used to determine the chemical composition of the coatings. The structure was investigated by X-ray diffraction in grazing incidence $\left(\alpha=4^{\circ}\right)$ and $\theta-2 \theta$ configurations, by using a Rigaku $\mathrm{A}\left(\mathrm{CuK}_{\alpha}\right.$ radiation $)$ and a Siemens $\left(\mathrm{CoK}_{\alpha}\right.$ radiation) diffractometer, respectively. The position and integral width of XRD peaks, for $\theta-2 \theta$ configuration, were determined to calculate the grain size from the Scherrer equation. Optical signatures of B-N vibrational modes were obtained by Fourier transform infrared spectroscopy (FTIR) in the absorbance mode from 400 to $2000 \mathrm{~cm}^{-1}$. Microhardness was measured dynamically using a Fischerscope H100 instrument fitted with a Vickers indenter. Six indentations were performed on each sample by applying a nominal load of $50 \mathrm{mN}$. The testing procedure, including the correction of the experimental results for geometrical defects in the indenter, thermal drift of the equipment and uncertainty in the initial contact is described elsewhere [9].

\section{Results and discussion}

\subsection{As-deposited coatings}

Table 1 presents the main characteristics of the asdeposited films. Concerning the chemical composition, the $\mathrm{B} / \mathrm{N}$ atomic ratio goes up with increasing $\mathrm{N}$ content, to a maximum value followed by a decrease. This behaviour is identical to that found for the W-Si-N system [10]. For the film deposited in non-reactive mode $\left(\mathrm{W}_{80} \mathrm{~B}_{20}, \mathrm{~B} / \mathrm{W}=0.25\right)$ there is a significant decrease in the $\mathrm{B}$ content of the film in comparison to the target content $\left(\mathrm{W}_{2} \mathrm{~B}, \mathrm{~B} / \mathrm{W}=0.5\right)$. This is attributed to the preferential re-sputtering of $\mathrm{B}$ compared with $\mathrm{W}$, since B has a lower atomic weight than W. For

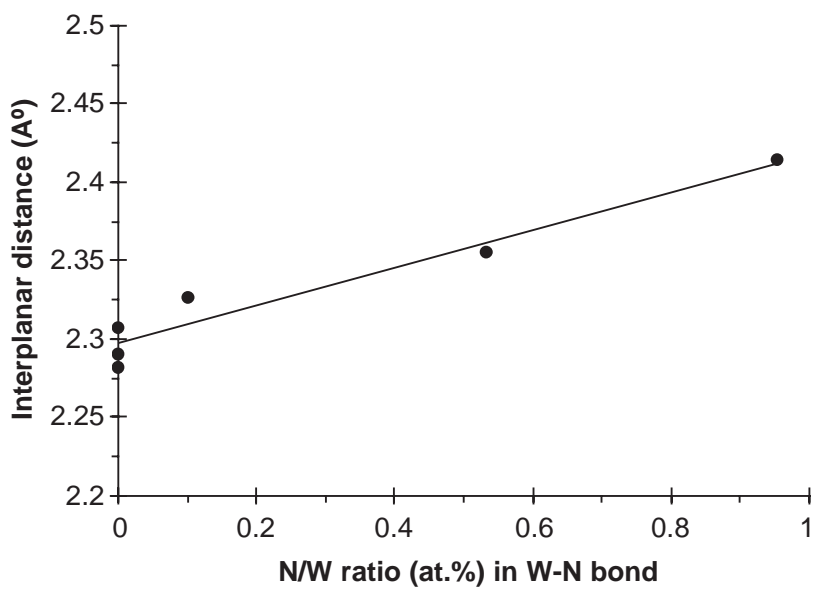

Fig. 1. As-deposited W-B-N coatings: interplanar distance vs. N/W atomic ratio in $\mathrm{W}-\mathrm{N}$ bond.

coatings deposited in a reactive atmosphere, it is expected that preferential formation of B-N bonds will occur, since the affinity of $\mathrm{B}$ for $\mathrm{N}$ is higher than that of $\mathrm{W}$ for $\mathrm{N}$ $\left(\Delta \mathrm{H}_{\mathrm{f}}^{\mathrm{W} 2 \mathrm{~N}}=-17 \mathrm{kcalmol}^{-1} ; \Delta \mathrm{H}_{\mathrm{f}}^{\mathrm{BN}}=-60.8 \mathrm{kcalmol}^{-1}[11]\right)$. These preferential bonds make boron re-sputtering from the growing film more difficult. As a consequence, the $\mathrm{B} / \mathrm{W}$ ratio increases. However, when the $\mathrm{N}$ content is higher than the atomic percentage of $\mathrm{B}$, besides $\mathrm{B}-\mathrm{N}, \mathrm{W}-\mathrm{N}$ bonds will also be formed. Thus, $\mathrm{W}$ re-sputtering will be made more difficult than that found for lower $\mathrm{N}$ content and consequently there will be a decrease in $\mathrm{B} / \mathrm{W}$ ratio as the $\mathrm{N}$ content increases in the film.

Considering the as-deposited structure, all the films present an amorphous structure characterised by two broad $\mathrm{X}$-ray peaks of low intensity as already reported [5]. In the single film, $\mathrm{W}_{60} \mathrm{~B}_{17} \mathrm{~N}_{23}$, signs of crystalinity were detected, which could be indexed as bec $\alpha-\mathrm{W}$ (ICDD 4-0806). In spite of the amorphous character of the films, the broad diffraction peaks shift toward lower angles as the $\mathrm{N}$ content increases (Table 1). The non-linearity of the increase of the interplanar distance with increasing $\mathrm{N}$ content can be attributed to the presence of $\mathrm{B}$, since this element influences the order and the arrangement of the atoms. According to the hypothesis that $\mathrm{B}$ combines preferentially with $\mathrm{N}$ before reacting with $\mathrm{W}$, the variation of the interplanar distance can be represented as a function of the N/W atomic ratio, Fig. 1.

Table 1

Characteristics of the as-deposited W-B-N sputtered films

\begin{tabular}{|c|c|c|c|c|c|c|c|c|c|}
\hline \multirow[t]{2}{*}{ Film } & \multirow[t]{2}{*}{ Thickness $(\mu \mathrm{m})$} & \multicolumn{4}{|c|}{ Chemical composition (at.\%) } & \multicolumn{3}{|c|}{ Structure } & \multirow[t]{2}{*}{ Hardness $(\mathrm{GPa})$} \\
\hline & & W & B & $\mathrm{N}$ & $\mathrm{B} / \mathrm{W}$ ratio & Phase & $d$ value $(\AA)$ & $\phi(\AA)$ & \\
\hline $\mathrm{W}_{80} \mathrm{~B}_{20}$ & 2.3 & 80.2 & 19.8 & - & 0.250 & $\mathrm{~A}^{*}$ & 2.2815 & 12 & $28 \pm 0.6$ \\
\hline $\mathrm{W}_{73} \mathrm{~B}_{24} \mathrm{~N}_{3}$ & 2.4 & 73.1 & 23.7 & 3.2 & 0.329 & A & 2.2909 & 11 & $27 \pm 1.1$ \\
\hline $\mathrm{W}_{68} \mathrm{~B}_{24} \mathrm{~N}_{8}$ & 2.8 & 67.9 & 24.5 & 7.6 & 0.353 & A & 2.3069 & 11 & $29 \pm 0.9$ \\
\hline $\mathrm{W}_{60} \mathrm{~B}_{17} \mathrm{~N}_{23}$ & 3.1 & 59.9 & 17.4 & 22.7 & 0.283 & $\begin{array}{l}\mathrm{A} \\
+\alpha-\mathrm{W}\end{array}$ & $\begin{array}{l}2.3264 \\
\left(a_{110}=3.244\right)\end{array}$ & $\begin{array}{l}13 \\
\left(\phi_{110}=179\right)\end{array}$ & $36 \pm 1.1$ \\
\hline $\mathrm{W}_{47} \mathrm{~B}_{14} \mathrm{~N}_{39}$ & 3.5 & 46.8 & 13.7 & 39.5 & 0.298 & A & 2.3551 & 12 & $27 \pm 0.5$ \\
\hline $\mathrm{W}_{42} \mathrm{~B}_{9} \mathrm{~N}_{49}$ & 2.8 & 41.8 & 8.6 & 49.6 & 0.214 & A & 2.4143 & 13 & $26 \pm 1.1$ \\
\hline
\end{tabular}

* amorphous phase. 
The $\mathrm{N}$ content, used for the calculation of the $\mathrm{N} / \mathrm{W}$ ratio represents the quantity that is not combined with the $\mathrm{B}$ in the form of B-N. Note that for nil N/W ratios the interplanar distance values are similar, while a good linear trend can be adjusted to the other N/W ratios. This dependence confirms that $\mathrm{N}$ will preferentially form $\mathrm{B}-\mathrm{N}$ bonds and, only after the total consumption of $\mathrm{B}$, will nitrogen react with tungsten. Nevertheless, no indication of B-containing phases is found in the recorded X-ray spectra, probably, since BN is a light compound.

In order to confirm the formation of $\mathrm{BN}$ phase, three coatings with similar $\mathrm{N}$ content were deposited onto (100) silicon wafers by reactive sputtering $(0.4 \mathrm{~Pa}$ for total deposition pressure and nitrogen partial pressure was settled at $0.2 \mathrm{~Pa}$ ). They were analysed by FTIR, which is the nondestructive method often used for identification of $\mathrm{BN}$
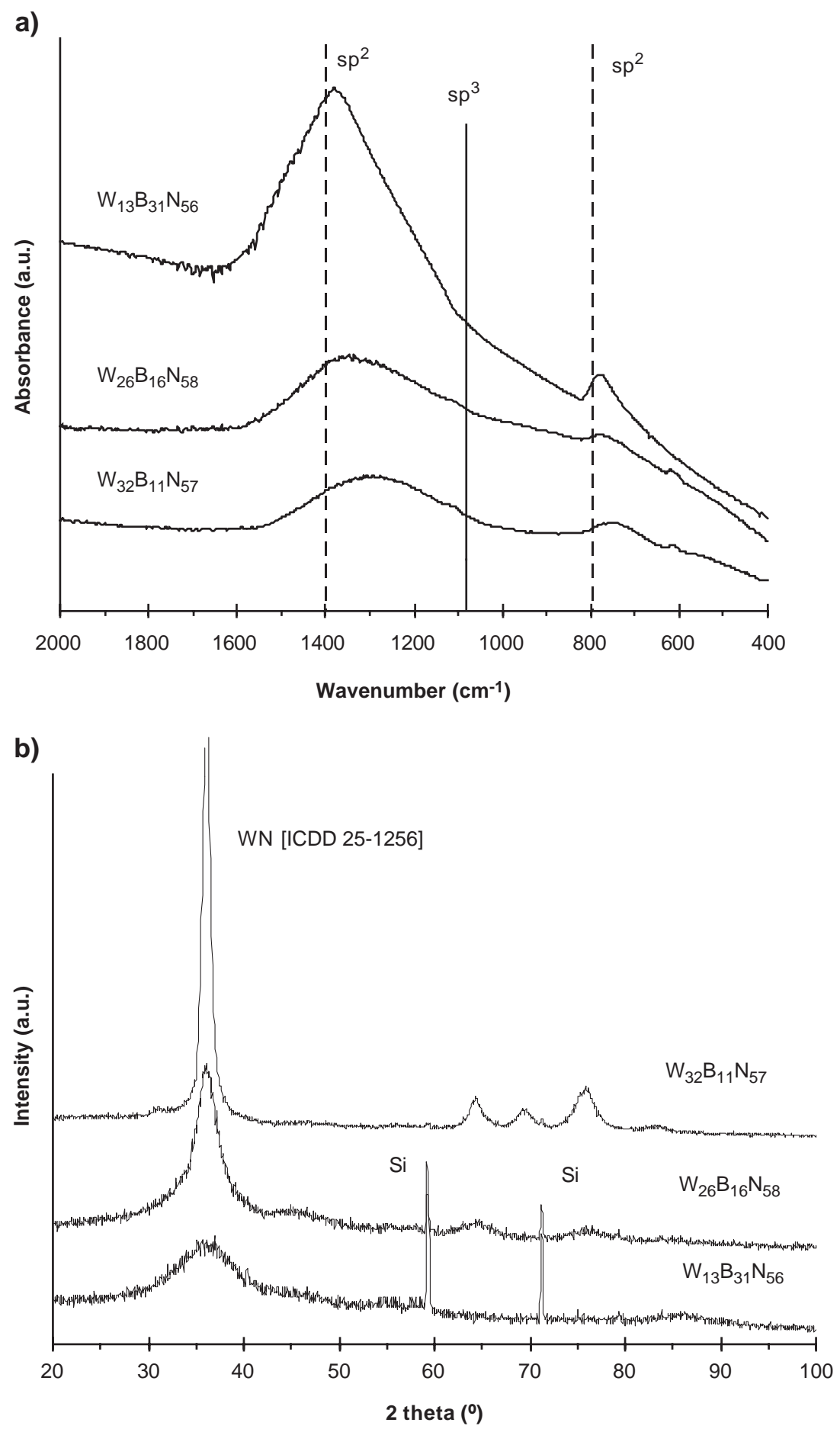

Fig. 2. Reactively sputter-deposited W-B-N films: a) FTIR spectra; b) X-ray diffractograms. 
phases [12-15]. The chemical composition of the films was varied, $\mathrm{W}_{13} \mathrm{~B}_{31} \mathrm{~N}_{56}, \mathrm{~W}_{26} \mathrm{~B}_{16} \mathrm{~N}_{58}$ and $\mathrm{W}_{32} \mathrm{~B}_{11} \mathrm{~N}_{57}$ by applying d.c. power of 15,30 and $60 \mathrm{~W}$ to the $\mathrm{W}$ target, respectively, while maintaining the B target r.f. power constant at $130 \mathrm{~W}$.

The IR adsorption spectra obtained are presented in Fig. 2a, while Fig. $2 \mathrm{~b}$ shows the GIXRD patterns. Turbostratic and hexagonal boron nitride share similar $\mathrm{sp}^{2}$-bonded structure, presenting the same two IR-active peaks at $\approx 800$ and 1400 $\mathrm{cm}^{-1}$, associated with out-of-plane B-N-B bond bending and in-plane $\mathrm{B}-\mathrm{N}$ bond stretching modes, respectively, while $\mathrm{sp}^{3}$ bonded c-BN show IR-active peak at $\approx 1080 \mathrm{~cm}^{-1}[13,14]$. The two absorption peaks observed in the FTIR spectra suggest that B-N bonds are formed. When the B content increases, the absorption peaks become stronger and both peaks shift towards higher wave numbers, indicating an increase in structural ordering and $\mathrm{sp}^{2}$ type of bonding.
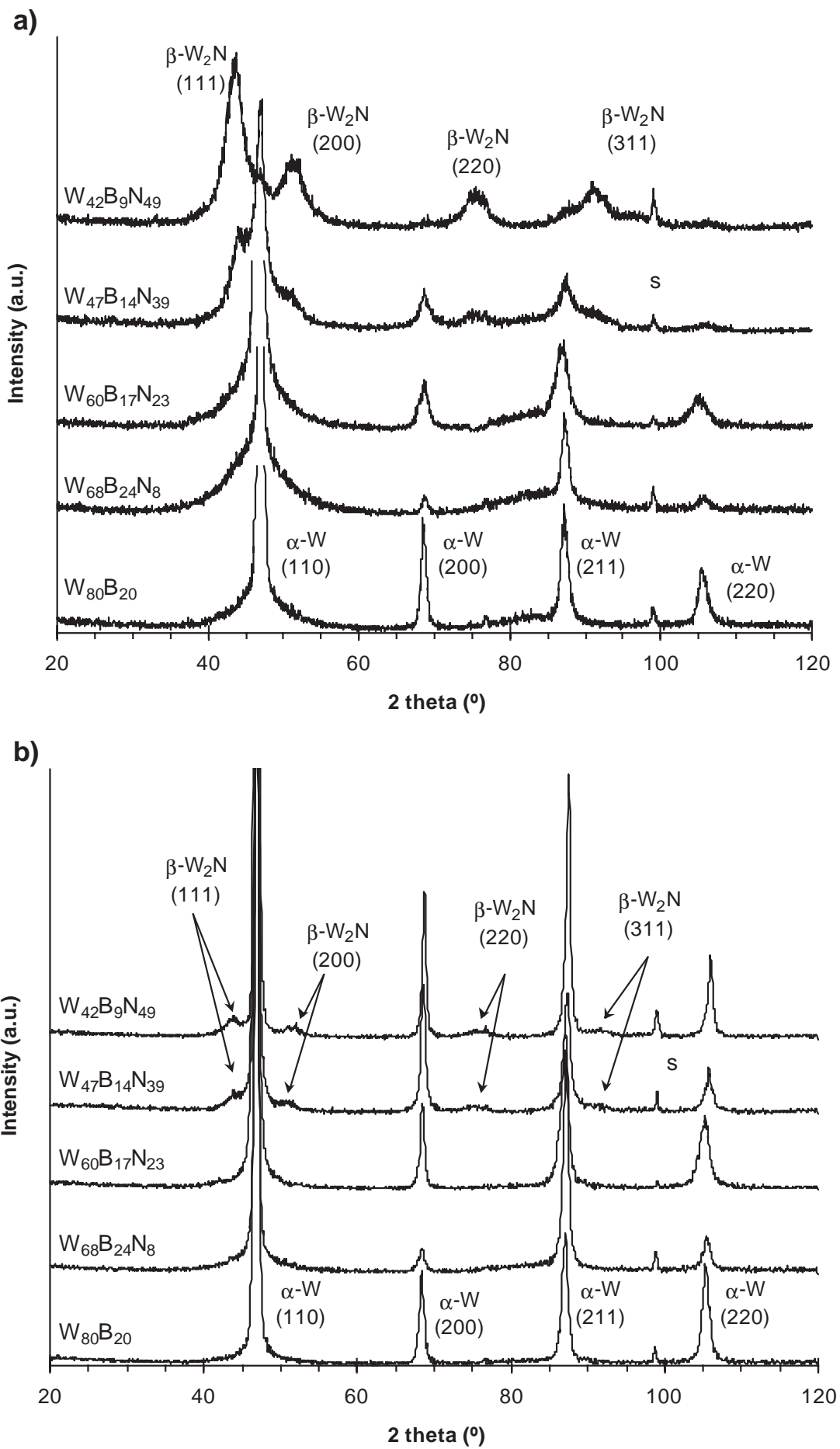

Fig. 3. Structural evolution of W-B-N films post-annealed: a) at $850{ }^{\circ} \mathrm{C} / 30 \mathrm{~min}$; b) at $950{ }^{\circ} \mathrm{C} / 30 \mathrm{~min}(s=\operatorname{substrate})$. 
The as-deposited hardness values (Table 1) correspond to those observed for other W-based sputtered amorphous coatings (about $28 \mathrm{GPa}$ [16]), but significantly larger than those reported for Ti-B-N amorphous coatings (about 12 $\mathrm{GPa}$ [17]). The $\mathrm{W}_{60} \mathrm{~B}_{17} \mathrm{~N}_{23}$ film has the highest hardness value: $36 \pm 1.1 \mathrm{GPa}$. In contrast to the other coatings, this film exhibits an amorphous matrix with embedded $\alpha-\mathrm{W}$ nanoparticles $(\phi=18 \mathrm{~nm})$, indicating that the morphology significantly influences the hardness.

\subsection{Annealed coatings}

The application of these coatings in mechanical components requires the study of their structural stability at high temperatures. W-B-N films were heat treated by cumulative thermal annealing at 850 and $950{ }^{\circ} \mathrm{C}$ (Fig. 3; Table 2).

The structural evolutions are in agreement with the type of bonding established in the as-deposited state. In particular, $\mathrm{N}$ is preferentially bonded to $\mathrm{B}$ and only the remaining free $\mathrm{N}$ reacts with $\mathrm{W}$. For films with $\mathrm{N}$ content lower than 25 at. $\%$, only the $\alpha-\mathrm{W}$ peaks are detected, because the $\mathrm{B}$ content is enough to consume the whole $\mathrm{N}$ available. For $\mathrm{N}$ content higher than 35 at. $\%$, besides the $\alpha$ $\mathrm{W}$ phase, the peaks corresponding to $\beta-\mathrm{W}_{2} \mathrm{~N}$ (ICDD 25 1257) are also present. Notice in Fig. $3 a$ that the $\mathrm{W}_{2} \mathrm{~N}$ phase is well developed with higher $\mathrm{N}$ content in the as-deposited films. The diffraction peaks are broad and their intensities are weak, which indicates that the crystalline $\mathrm{W}_{2} \mathrm{~N}$ structure is less ordered, probably due to small crystal sizes. The formation of $\beta-\mathrm{W}_{2} \mathrm{~N}$, as a crystallisation product in $\mathrm{W}$-based

Table 2

Characteristics of W-B-N sputtered films after thermal annealing in an Ar/ $\mathrm{H}_{2}$ atmosphere

\begin{tabular}{|c|c|c|c|c|c|}
\hline \multirow[t]{2}{*}{ Film } & \multirow[t]{2}{*}{$T\left({ }^{\circ} \mathrm{C}\right)$} & \multicolumn{3}{|l|}{ Structure } & \multirow{2}{*}{$\begin{array}{l}\begin{array}{l}\text { Mechanical } \\
\text { properties }\end{array} \\
\mathrm{Hv}(\mathrm{GPa})\end{array}$} \\
\hline & & Phases & $\begin{array}{l}a_{(\mathrm{hkl})} \\
(\AA)\end{array}$ & $\begin{array}{l}\phi_{(\mathrm{hkl})} \\
(\AA)\end{array}$ & \\
\hline \multirow[t]{3}{*}{$\mathrm{W}_{80} \mathrm{~B}_{20}$} & RT & $\mathrm{A}^{*}$ & - & - & $28 \pm 0.6$ \\
\hline & 850 & $\alpha-W+A$ & 3.1789 & 155 & $29 \pm 1.0$ \\
\hline & 950 & $\alpha-W+A$ & 3.1824 & 187 & $29 \pm 1.3$ \\
\hline \multirow[t]{3}{*}{$\mathrm{W}_{73} \mathrm{~B}_{24} \mathrm{~N}_{3}$} & RT & A & - & - & $27 \pm 1.1$ \\
\hline & 850 & $\alpha-W+A$ & 3.1786 & 141 & $32 \pm 1.9$ \\
\hline & 950 & $\alpha-W+A$ & 3.1809 & 191 & $26 \pm 1.6$ \\
\hline \multirow[t]{3}{*}{$\mathrm{W}_{68} \mathrm{~B}_{24} \mathrm{~N}_{8}$} & RT & A & - & - & $29 \pm 0.9$ \\
\hline & 850 & $\alpha-W+A$ & 3.1785 & 125 & $31 \pm 0.9$ \\
\hline & 950 & $\alpha-W+A$ & 3.1799 & 181 & $28 \pm 1.6$ \\
\hline \multirow[t]{3}{*}{$\mathrm{W}_{60} \mathrm{~B}_{17} \mathrm{~N}_{23}$} & RT & $\alpha-\mathrm{W}+\mathrm{A}$ & 3.2440 & 179 & $36 \pm 1.1$ \\
\hline & 850 & $\alpha-W+A$ & 3.1924 & 78 & $33 \pm 0.6$ \\
\hline & 950 & $\alpha-W+A$ & 3.1833 & 170 & $22 \pm 2.0$ \\
\hline \multirow[t]{4}{*}{$\mathrm{W}_{47} \mathrm{~B}_{14} \mathrm{~N}_{39}$} & RT & A & - & - & $27 \pm 0.5$ \\
\hline & 850 & $\alpha \mathrm{W}+$ & $3.1847 /$ & $123 / 35$ & $29 \pm 1.0$ \\
\hline & & $\mathrm{W}_{2} \mathrm{~N}+\mathrm{A}$ & 4.142 & & \\
\hline & 950 & $\alpha-W+A$ & 3.1728 & 216 & $8 \pm 0.2$ \\
\hline \multirow[t]{3}{*}{$\mathrm{W}_{42} \mathrm{~B}_{9} \mathrm{~N}_{49}$} & 25 & A & - & - & $26 \pm 1.1$ \\
\hline & 850 & $\begin{array}{l}\alpha \mathrm{W}+\mathrm{W}_{2} \mathrm{~N} \\
+\mathrm{A}\end{array}$ & $\begin{array}{l}3.1853 / \\
4.176\end{array}$ & $29 / 33$ & $28 \pm 0.6$ \\
\hline & 950 & $\alpha-\mathrm{W}+\mathrm{A}$ & 3.1691 & 231 & $5 \pm 0.1$ \\
\hline
\end{tabular}

* amorphous phase. films, is an unexpected result. Both W-N and W-Si-N sputtered systems liberate nitrogen around $800{ }^{\circ} \mathrm{C}$ in vacuum $[3,18]$, unless an atmosphere containing nitrogen is used [19]. The crystallisation of $\mathrm{W}_{2} \mathrm{~N}$ at $850{ }^{\circ} \mathrm{C}$ can only be explained by the presence of $\mathrm{B}$. As the annealing temperature increases, no important changes in the structural behaviour is detected in the low $\mathrm{N}$ content films (Fig. 3b), with the exception of a further reduction in the amorphous phase expressed by a narrowing of the diffraction peaks, suggesting a strong increase in the grain size (see Table 2). Besides, for the high $\mathrm{N}$ content films, a significant loss of nitrogen occurs, since the binary phase $\mathrm{W}_{2} \mathrm{~N}$ almost disappears. The remaining amount of $\mathrm{N}$ in the films corresponds to the $\mathrm{B}$ content capable of retaining it in the form of $\mathrm{BN}$ phase.

In none of the coatings can any crystalline boron-based phases be detected by XRD. The same can be said for tungsten borides, which should be expected, particularly in the films with low $\mathrm{N}$ content. In fact, for films containing $\mathrm{N}$ content less than 10 at.\%, the B content is high enough to form W-B binary phases, in a similar way as silicide phases were detected for comparable compositions in W-Si-N system $[3,19]$. Thus, the phase transition during heat treatment in addition to structural parameters values, obtained after deconvolution of the main diffraction peaks, can then be summarised as follows:

- For low N content films, the bcc $\alpha-\mathrm{W}$ phase is formed incorporating some $\mathrm{B}$ atoms, which allows a significant thermal stability without precipitation of W-B compounds and suppress grain growth. Small amounts of BN phase should be formed whose quantity will depend of the $\mathrm{N}$ content.

- For high $\mathrm{N}$ content films, the fcc $\beta-\mathrm{W}_{2} \mathrm{~N}$ phase crystallises directly from the amorphous phase including also some content of B. At $950{ }^{\circ} \mathrm{C}$, this phase decomposes in the $\alpha-\mathrm{W}$ and BN phases, due to the low stability of W-N bonds. The $\alpha-\mathrm{W}$ phase presents a lattice parameter similar to the standard value indicating the absence of incorporation of $\mathrm{B}$ or $\mathrm{N}$ in the lattice. The strong increase in the grain size $(\phi>20 \mathrm{~nm})$ suggests that the B-N phase does not precipitate at the grain boundaries of the $\alpha-\mathrm{W}$ phase which would impede grain coarsening.

Fig. 4a shows the composition dependence of the hardness of W-B-N sputtered films before and after thermal annealing. All the films keep the hardness at $850{ }^{\circ} \mathrm{C}$ of the as-deposited state, followed by a decrease after cumulative annealing at higher temperatures. A small increase in hardness at $850{ }^{\circ} \mathrm{C}$ can be related with the crystallisation of the films. Concurrent analyses of the hardness and of the structural parameter summarised in Table 2, suggest that a connection exist between the mechanical properties and the microstructure of the films. For the $\mathrm{W}_{80} \mathrm{~B}_{20}, \mathrm{~W}_{73} \mathrm{~B}_{24} \mathrm{~N}_{3}$ and $\mathrm{W}_{68} \mathrm{~B}_{24} \mathrm{~N}_{8}$ films, which present the same structural behaviour, the precipitation of small bcc crystallites appears to be 
a)

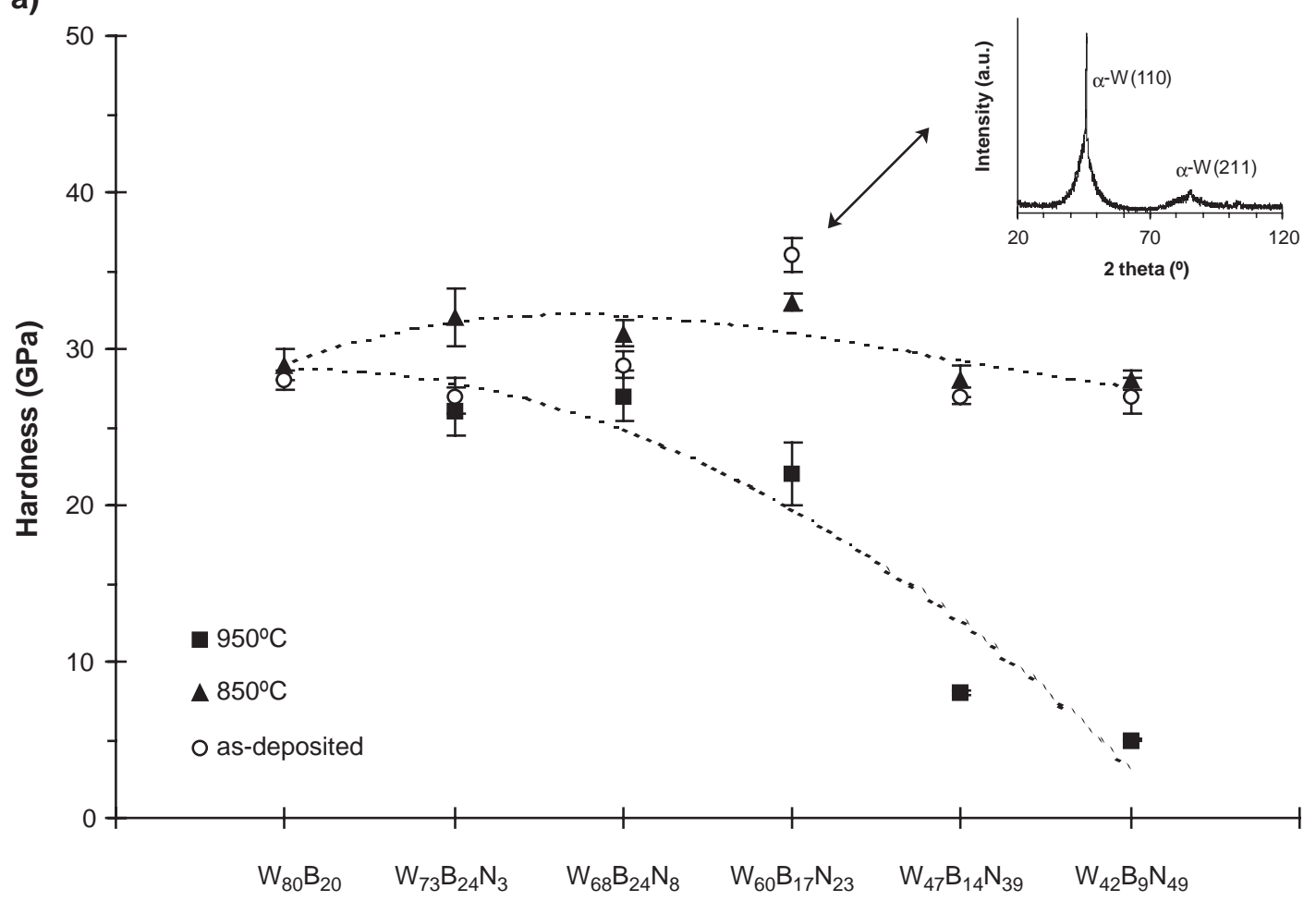

b)

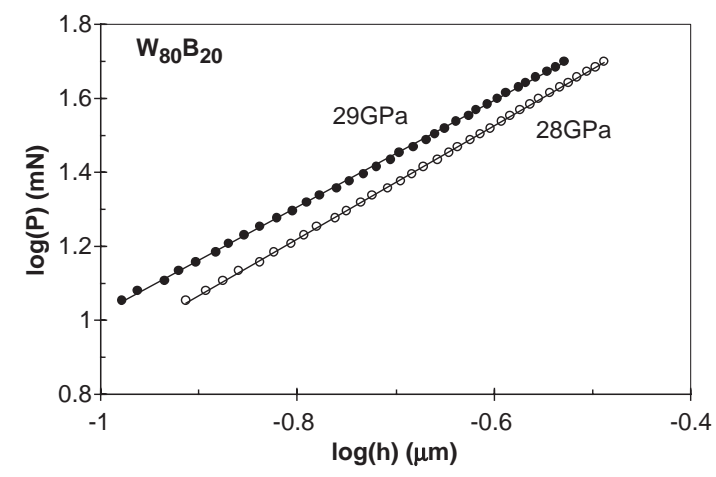

c)

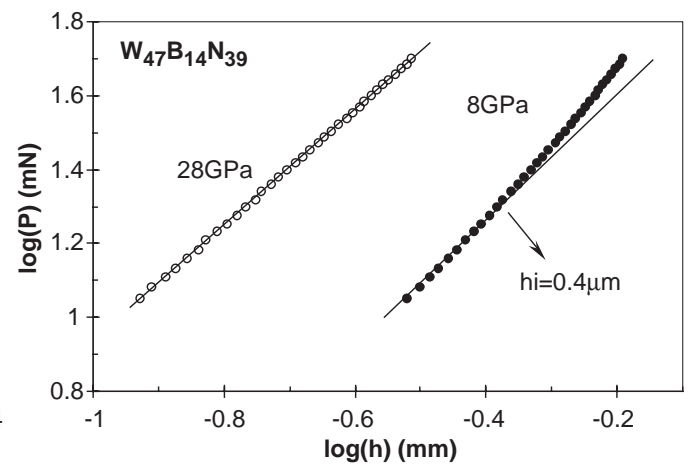

Fig. 4. a) Hardness evolution of W-B-N films before and after thermal annealing; b) and c) loading part of the indentation load vs. indentation depth curves (logarithmic scale) of the $\mathrm{W}_{80} \mathrm{~B}_{20}$ and $\mathrm{W}_{47} \mathrm{~B}_{14} \mathrm{~N}_{39}$ coatings, respectively, after deposition and after thermal treatment at $950{ }^{\circ} \mathrm{C}$.

the most significant effect on the observed increase of the hardness at $850{ }^{\circ} \mathrm{C}$, since the lattice parameter is almost constant for the three films. The sharp decreases after the $950{ }^{\circ} \mathrm{C}$ annealing reveal different origin. With the increase of the annealing temperature, the grain sizes and lattice parameters increase. Thus, grain growth seems to be the main factor contributing to the observed softening.

Fig. $4 \mathrm{~b}$ and $\mathrm{c}$ shows the loading parts of the indentation curves (on logarithmic scale) for the $\mathrm{W}_{80} \mathrm{~B}_{20}$ and $\mathrm{W}_{47} \mathrm{~B}_{14} \mathrm{~N}_{39}$ coatings, both as-deposited and after thermal treatment at $950{ }^{\circ} \mathrm{C}$. The deviation from the linear dependence presented by $\mathrm{W}_{47} \mathrm{~B}_{14} \mathrm{~N}_{39}$ film, Fig. $4 \mathrm{c}$, is not observed for the film deposited in non-reactive mode (Fig. 4b). The deviation from the linear dependence corresponds to a critical indentation depth (hi), according to the empirical model proposed by J.V. Fernandes et al. [20], from which it is possible to separate an external soft phase (with minor slope) followed by an internal hard layer (with larger slope). The soft layer can only be the BN phase, according to the previous structural analysis. In fact, the decrease of the bcc lattice parameter of both $\mathrm{W}_{47} \mathrm{~B}_{14} \mathrm{~N}_{39}$ and $\mathrm{W}_{42} \mathrm{~B}_{9} \mathrm{~N}_{49}$ samples with increasing annealing temperature in addition to the suppression of $\beta-\mathrm{W}_{2} \mathrm{~N}$, indicates the absence of incorporation of $\mathrm{B}$ or $\mathrm{N}$ atoms in the $\alpha-\mathrm{W}$ lattice. Notice that the lattice parameter measured for $\mathrm{W}_{42} \mathrm{~B}_{9} \mathrm{~N}_{49}$ is similar to the standard value of $\alpha$-W (3.1648 $\AA$ ). This behaviour suggests that multilayers coatings are formed for high $\mathrm{N}$ content $\mathrm{W}$ B-N films post-annealed at $950{ }^{\circ} \mathrm{C}$. Further understanding of these results is expected by ongoing research work with SEM and TEM analysis. 


\section{Conclusions}

This study demonstrates that amorphous W-B-N thin films with increasing $\mathrm{N}$ contents, from 0 to 50 at.\%, can be reactively sputter-deposited from a $\mathrm{W}_{2} \mathrm{~B}$ target. Heat treatment allows attaining multiphase nanocrystalline films. The structural evolutions, including the phase composition, grain size and lattice parameter, depend on $\mathrm{B}$ and $\mathrm{N}$ content. For $850{ }^{\circ} \mathrm{C}$ annealing temperature a small hardness increases were obtained. Annealing at the higher temperature $\left(950{ }^{\circ} \mathrm{C}\right)$ is responsible for a sharp decrease in hardness. The obtained indentation load curves suggest that an external soft BN film forms at this temperature with such behaviour becoming more pronounced with increasing $\mathrm{N}$ content in the film. Finally, it can be concluded that the mechanical behaviour evaluated by the hardness of the W-B-N post-annealed films is not significantly improved. Nevertheless, the presence of an h-BN phase in the coating can be beneficial for dry machining applications.

\section{References}

[1] Hari Singh Nalwa, Handbook of Nanostructured Materials and Nanotechnology, vol. 1, Academic Press, 2000, p. 260.

[2] M.T. Vieira, A. Cavaleiro, B. Trindade, Surf. Coat. Technol. 151-152 (2002) 495.

[3] C. Louro, A. Cavaleiro, Surf. Coat. Technol. 123 (2000) 192.
[4] C. Louro, Surf. Coat. Technol. 180-181 (2004) 544

[5] J.S. Reid, R.Y. Liu, Paul Martin Smith, R.P. Ruiz, M.-A. Nicolet, Thin Solid Films 262 (1995) 218.

[6] J.S. Byun, A. Mak, A. Zhang, A. Yoon, et al., J. Vac. Sci. Technol., B 21 (4) (2003) 1466.

[7] D.J. Kim, H.S. Sim, S.-II. Kim, Y.T. Kim, H. Jeon, J. Vac. Sci. Technol., A 20 (1) (2002) 194.

[8] D.J. Kim, Y.T. Kim, J.-W. Park, J. Vac. Sci. Technol., B 17 (4) (1999) 1598.

[9] J.M. Antunes, A. Cavaleiro, L.F. Menezes, M.I. Simões, J.V. Fernandes, Surf. Coat. Technol. 149 (2002) 27.

[10] C. Louro, A. Cavaleiro, F. Montemor, Surf. Coat. Technol. 142-144 (2001) 964.

[11] H.J. Goldschmidt, Interstitial Alloys, Butterworth and Co (1967) Chap5, pp. 220 and 235.

[12] M.A. Djouadi, O. Banakh, A. Soltani, R. Sanjines, F. Levy, Thin Solid Films 398-399 (2001) 205.

[13] Y. Setsuhara, M. Kumagai, M. Suzuki, S. Miyake, Surf. Coat. Technol. 116/119 (1999) 100.

[14] C. Hu, S. Kotake, Y. Suzuki, M. Senoo, Vacuum 59 (2000) 748.

[15] J.L. He, S. Miyake, Y. Setsuhara, I. Shimizu, M. Suzuki, K. Numata, H. Saito, Wear 249 (2001) 498.

[16] A. Cavaleiro, C. Louro, Vacuum 64 (2002) 211.

[17] R. Wiedmann, V. Weihnacht, H. Oettel, Surf. Coat. Technol. 116/119 (1999) 302.

[18] J.S. Reid, E. Kolawa, R.P. Ruiz, M.-A. Nicolet, Thin Solid Films 236 (1993) 319.

[19] L. Ferreira, C. Louro, A. Cavaleiro, B. Trindade, Key Eng. Mater. 230/232 (2002) 640.

[20] J.V. Fernandes, A.C. Trindade, L.F. Menezes, A. Cavaleiro, J. Mater. Res. 15 (2000) 1766. 